\title{
RESEARCH
}

Open Access

\section{Socioeconomic determinants and inequalities in the prevalence of non- communicable diseases in Saudi Arabia}

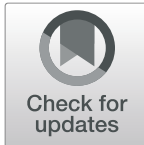

Mohammed Khaled Al-Hanawi ${ }^{1,2}$

\begin{abstract}
Background: Non-communicable diseases (NCDs) are increasingly becoming a challenge worldwide, causing high mortality and morbidity. Saudi Arabia has one of the highest rates of NCDs globally and the highest in the Arabian Gulf region. Epidemiological data indicate that NCDs are responsible for $70 \%$ of all deaths in Saudi Arabia. The aim of this study was to examine the socioeconomic determinants and inequalities in the prevalence of NCDs in Saudi Arabia.
\end{abstract}

Methods: Data from the Saudi Family Health Survey conducted in 2018 by the General Authority for Statistics were used for this study. Univariate, bivariate, and multivariate logistic regression analyses were employed to examine the socioeconomic factors associated with the prevalence of NCDs. Moreover, the concentration curve and concentration indices were used to assess inequalities in the prevalence of NCDs.

Results: Among the 11,527 respondents, the prevalence of NCDs was $32.15 \%$. The prevalence of NCDs was higher among women and among elderly respondents aged $\geq 60$ years. With respect to the determinants of the prevalence of NCDs, the logistic regression results showed that the likelihood of reporting NCDs was lower among people with a higher education (OR: 0.599, $95 \%$ Cl: $0.497-0.723, p<0.01$ ) compared with that of people with an education below the primary school level. Other factors significantly associated with the prevalence of NCDs were age, marital status, nationality, and region of residence. The inequality analysis showed that at the national level, the prevalence of NCDs was concentrated among less educated people (concentration index $=-0.338, p<0.01$ ), but with significant regional variations. Gender disaggregation showed that both income-based and education-based concentration indices were significantly negative among women, indicating that the prevalence of NCDs is concentrated among women with a lower income level and with less education.

Conclusions: The findings of this study are important for policymakers to combat both the increasing prevalence of and socio-economic inequalities in NCDs. The government should develop targeted intervention strategies to control NCDs and achieve health equality considering socio-economic status. Future policies should target women and the lower educated population in Saudi Arabia.

Keywords: Inequalities, Non-communicable diseases, Public health, Saudi Arabia, Socio-economic status

\footnotetext{
Correspondence: mkalhanawi@kau.edu.sa

${ }^{1}$ Department of Health Services and Hospital Administration, Faculty of

Economics and Administration, King Abdulaziz University, Jeddah, Saudi

Arabia

${ }^{2}$ Health Economics Research Group, King Abdulaziz University, Jeddah, Saudi

Arabia
}

(C) The Author(s). 2021 Open Access This article is licensed under a Creative Commons Attribution 4.0 International License, which permits use, sharing, adaptation, distribution and reproduction in any medium or format, as long as you give appropriate credit to the original author(s) and the source, provide a link to the Creative Commons licence, and indicate if changes were made. The images or other third party material in this article are included in the article's Creative Commons licence, unless indicated otherwise in a credit line to the material. If material is not included in the article's Creative Commons licence and your intended use is not permitted by statutory regulation or exceeds the permitted use, you will need to obtain permission directly from the copyright holder. To view a copy of this licence, visit http://creativecommons.org/licenses/by/4.0/ The Creative Commons Public Domain Dedication waiver (http://creativecommons.org/publicdomain/zero/1.0/) applies to the data made available in this article, unless otherwise stated in a credit line to the data. 


\section{Introduction}

Over the past few decades, the epidemiological progression of diseases has shifted from predominantly communicable diseases towards non-communicable diseases (NCDs) [1]. NCDs, also known as chronic diseases, tend to be of long duration and are the result of a combination of genetic, physiological, behavioural, and environmental factors. This shift to a predominance of NCDs is also attributable to demographic, economic, and environmental changes over time [2]. These changes include the effects of increasing tobacco and alcohol use, physical inactivity, and unhealthy habits, which are the main risk factors associated with the rapid rise in NCDs [3].

The burden of NCDs remains a global public health challenge, leading to high mortality and morbidity. Constituting chronic illnesses that are not infectious or contagious in nature, NCDs are the largest cause of premature death worldwide [4]. According to the World Health Organization (WHO), NCDs kill approximately 41 million people annually, accounting for $71 \%$ of all deaths globally [5]. The main types of NCDs are cardiovascular diseases, chronic respiratory diseases, hypertension, diabetes, and cancers.

Global demographic data suggest that the global population has evolved tremendously. NCDs have spread from the Western hemisphere to global populations. Notably, countries in the Middle East, including the Kingdom of Saudi Arabia (KSA), have experienced this transition [6]. An analysis of the proportional distribution of causes of mortality in 1990-2010 and 2010-2017 in the KSA revealed that NCDs remained relatively stable in both time periods. Even though cardiovascular mortality increased between 1990 and 2010, it remained roughly stable between 2010 and 2017 [6]. However, a review of the wider literature revealed that although the proportional cause of death of NCDs has remained stable in the KSA, the prevalence of NCDs has actually increased.

One study found that the prevalence of hypertension is increasing in the KSA, affecting $26.1 \%$ of the adult population [7]. Other NCDs such as metabolic syndrome, diabetes mellitus, obesity, and dyslipidaemia are also on the rise in the KSA $[8,9]$. A recent study showed that increasing physical inactivity and maintenance of an unhealthy diet have led to an increase in the prevalence of these NCDs in the KSA [10]. Evidence suggests that the prevalence of diabetes mellitus, hypertension, and dyslipidaemia in the KSA increased from $9.7 \%, 11.4 \%$, and $9 \%$ in the $1970 \mathrm{~s}$ to $26.2 \%, 28.6 \%$, and $18.6 \%$, respectively, in 2000-2009 among men [11].

There are two main reasons for the increased prevalence of NCDs in the KSA. First, there has been an increasing trend towards unhealthy lifestyles and harmful health behaviours, which may explain the changes in the disease patterns that have shifted from predominantly communicable diseases towards NCDs [12]. Second, there has been an improvement in human longevity in the KSA, as evidenced by an increase in life expectancy from 64 years in the $1980 \mathrm{~s}$ to 74 years in the $2000 \mathrm{~s}$ [13]. This increase in life expectancy has caused a tandem increase in the prevalence of NCDs, which rises with age [14].

The effects of NCDs are largely prolonged, thereby requiring long-term care and attention. Unlike other diseases with a substantial burden in developing countries, NCDs are a challenge to low-, middle-, and high-income countries alike [15]. Aside from premature death, NCDs undermine social and economic development [16]. The potential of NCDs to reduce quality of life and alter healthcare costs highlights the need to institute operational prevention and control mechanisms. Furthermore, NCDs exacerbate the inequality gaps in health relating to people's health condition and healthcare access. Inequality in the prevalence of NCDs is one of the leading causes of inequality in life expectancy and mortality [17]. This inequality has attracted substantial attention from several researchers.

In particular, there has been extensive research on the inequalities in the prevalence of NCDs in low-, middle-, and high-income countries $[15,18]$. However, there is a scarcity of literature in the KSA regarding the socioeconomic inequalities in the prevalence of NCDs. Previous studies on NCDs have mainly focused on assessing prevalence rates, without taking into account the dimension of income and education-related inequalities, which are crucial factors for policy intervention. Additionally, the bulk of available studies have analysed specific types of chronic NCDs and did not use nationally representative data owing to the scarcity of such data.

To the best of the author's knowledge, there is no study from the KSA that has analysed the socioeconomic inequalities in the prevalence of NCDs. Specifically, no study has used concentration indices to examine the inequality dimensions of NCDs. Therefore, the aim of this study was to fill this gap in the literature by employing univariate, bivariate, and multivariate logistic regression analyses to examine the socioeconomic factors associated with the prevalence of NCDs in the KSA. Moreover, the socio-economic inequalities in the prevalence of NCDs were determined by employing concentration indices and concentration curves. Unlike most of the aforementioned studies, this study used a recent rich dataset that has national representativeness and focused on economic consequences, thereby providing useful guidance on building effective health policies and interventions to curtail the burden of NCDs in the KSA.

The KSA is a compelling case to examine these types of socio-economic inequalities on several grounds. 
Firstly, Saudi Arabia has one of the highest rates of NCDs in the world and the highest in the Arabian Gulf region. Epidemiological data indicate that NCDs are responsible for $70 \%$ of all deaths in the KSA [19]. Secondly, inherent inequalities between men and women, and across regions in the country make the KSA an interesting case to examine the prevalence of NCDs on such inequalities. Lastly, the healthcare system in Saudi Arabia occupies a large share of the national budget and is undergoing improvement in line with Saudi Vision 2030. Accordingly, this study is both relevant and timely for the conceptualization and implementation of adjustments to the healthcare system of the KSA.

\section{Materials and methods}

\section{Study setting}

This study was conducted in the KSA, the largest country in the Middle East with a land size of approximately $2,150,000 \mathrm{~km}^{2}$. The KSA is one of the largest oil producer and exporter countries in the world, and is one of the most important Islamic heritage sites [20]. The KSA relies heavily on oil revenues for its economy, which are used to finance most public sectors, including the healthcare sector [21]. According to the World Bank, the KSA is classified as a high-income country with a high Human Development Index [22]. The KSA also has one of the youngest populations in the world, with 19.6 million people under the age of 30 , representing about $57 \%$ of the total population [23].

\section{Data}

Self-weighted data from the Saudi Family Health Survey (FHS) conducted in 2018 by the General Authority for Statistics (GaStat) [24] were used in this study. The FHS is the first collaborative stage between GaStat and several entities in the health sector in the Kingdom, such as the Ministry of Health, the Saudi Health Council, as well as the private and academic sectors. The FHS is a field survey conducted by GaStat every three years, which falls under the classification of education and health statistics. The FHS collects information by visiting a representative sample of the population across all administrative regions in the KSA.

The survey questionnaire was drafted and designed by health statistics experts at GaStat. International recommendations, standards, and definitions issued by the WHO were taken into consideration during the design of the questionnaire. The survey contains several questions to collect information relating to geographical data, basic information of household members, marriage and family planning data, fertility and mortality data, family income and expenditure, and health status of individuals, including if they suffer from any chronic diseases, among other topics [24]. The FHS collected a total sample of
15,265 responses randomly selected across all 13 regions of the Kingdom. For this study, the analysis was limited to respondents who provided complete information on all variables of interest. Therefore, this analysis was based on a sample of 11,527 respondents.

\section{Measurements}

The FHS collected information on the health status of individuals, including a question asking if they suffer from any chronic diseases. This question was given a value of 1 for a response of "yes" and 0 for a response of "no". This binary variable was then used as the dependent variable for examining the socio-economic determinants and inequalities in the prevalence of chronic NCDs in the KSA.

Other socio-economic and demographic characteristics, including age, gender, marital status, nationality, education level, monthly income, and region of residence, were used as independent variables, with income and education level used as the socio-economic status indicators among the respondents. The age variable was divided into five categories: 18 to 29 (reference category), 30 to 39,40 to 49,50 to 59 , and $\geq 60$ years. Gender was assigned a value of 1 if the respondent was a man and 0 if the respondent was a woman. Marital status was also captured as a binary variable, with a value of 1 given for married respondents and 0 for unmarried respondents (including never married, divorced, and widowed). Nationality was given a value of 1 if the respondent was Saudi and 0 if non-Saudi. Education level was grouped as follows: below primary school (reference), primary school, intermediate school, high school, and higher education. Monthly income [in Saudi Riyal (SR); $1 \mathrm{SR}=$ USD 0.27] was grouped into eight categories: less than SR 3000 (reference category), SR 3000 to < 5000, SR 5000 to $<7000$, SR 7000 to $<10,000$, SR 10,000 to $<15,000$, SR 15,000 to $<20,000$, SR 20,000 to < 30,000 , and SR 30,000 or more. To account for regional differences, the region variable was grouped into the 13 administrative regions: Riyadh (reference), Albaha, Aljouf, Aseer, Eastern Region, Haiel, Jazan, Madenah, Mekkah, Najran, Northern Borders, Qaseem, and Tabouk.

\section{Statistical analysis}

Univariate analysis was first employed to estimate the percentages and frequencies of respondents for the characteristics of interest. Bivariate analysis was also employed to cross-tabulate the dependent variable and measure the associated frequencies using a Chi-squared test. Multivariate logistic regression models were estimated to examine the socio-economic factors associated with the prevalence of NCDs. Different models were estimated after controlling for age, gender, marital status, 
nationality, and region of residence. Given that covariate measurement error via misclassification of categorical independent variables in the regression analysis may potentially pose a threat to the validity of parameter estimates and statistical inferences, the study conducted a sensitivity analysis via re-estimation by bootstrap and jackknife approaches [25]. Additionally, the methodology of Wagstaff et al. [26] was adopted to measure socio-economic inequalities in the prevalence of NCDs. This includes visualisation and estimation of inequalities using the concentration curve and the concentration index. Moreover, apart from understanding the general inequality at the national level, the study measured gender and regional inequalities in the prevalence of NCDs which are the common variables by which disparities in health occur as per literature [9, 27-29].

The concentration curve plots the cumulative percentage of a health variable on the vertical axis against the cumulative share of that variable in the population (ranked from the lowest to the highest by an indicator of the socio-economic status) on the horizontal axis. A concentration curve above the line of equality indicates that the prevalence of NCDs is concentrated among the poor, whereas a concentration curve below the line of equality indicates that the prevalence of NCDs is concentrated among the rich. Similarly, with respect to education, a concentration curve above the line of equality indicates that the prevalence of NCDs is concentrated among the less educated and a concentration curve below the line of equality indicates that the prevalence of NCDs is concentrated among the well-educated people. The further the concentration curve diverges from the line of equality (i.e. the 45-degree line), the greater the degree of inequality. The concentration index was calculated as twice the area between the concentration curve and the line of equality to quantify the degree of socio-economic-related inequality in a health sector variable [30]. The concentration index ranges between 1 and +1 , whereby a positive index indicates that the prevalence of NCDs is disproportionately concentrated among the rich and a negative index indicates concentration among the poor. Similarly, with respect to education, a negative concentration index indicates that the prevalence of NCDs is concentrated among the less educated and a positive concentration index indicates concentration among the well-educated people.

\section{Ethical clearance}

This study was based on the use of secondary data from the FHS, which was conducted, commissioned, funded, and managed in 2018 by GaStat that was in charge of all ethical procedures. All procedures performed in this study involving human participants complied with the institutional and/or national research committee ethical standards, and with the 1964 Helsinki Declaration and subsequent amendments or equivalent ethical standards. Informed consent was obtained from all participants. All personal identifiers were removed from the dataset by GaStat to allow for secondary data use. GaStat granted permission to use the data and thus no further clearance was necessary as this was performed at the data collection phase.

\section{Results \\ Descriptive statistics}

Among the total sample of 11,527 respondents, $32.15 \%$ reported suffering from NCDs. Approximately one-third of the sample was in the age range of $18-29$ years, $55 \%$ were men, and two-thirds of the sample were married. With respect to education level, $19.32 \%$ of the respondents had no schooling or below primary school education and $19.88 \%$ completed higher education. Table 1 shows the full characteristics of the sample.

\section{Bivariate analysis}

Table 2 shows the results of bivariate analysis of the association between the prevalence of NCDs and socioeconomic characteristics. The prevalence of NCDs was significantly associated with gender $\left(\mathrm{X}^{2}=10.51, p<0.01\right)$, in which NCDs were more concentrated among women $(33.68 \%)$ than men $(30.86 \%)$. There were significant associations between the prevalence of NCDs and marital status $\left(x^{2}=404.21, p<0.01\right)$ and region of residence $\left(x^{2}=274.39, p<0.01\right)$. Moreover, there was a significant association between the prevalence of NCDs and educational attainment $\left(x^{2}=160.63, p<0.01\right)$. Compared with that of highly educated people $(20.07 \%)$ and those with secondary school education (17.98\%), the prevalence of NCDs was much higher among people with no schooling or with a below primary school level of education (64.11\%). Moreover, the prevalence of NCDs was significantly associated with nationality $\left(x^{2}=275.76, p<\right.$ 0.01 ), in which the prevalence of chronic diseases was more heavily concentrated among Saudis (36.32\%) than non-Saudis (19.64\%).

To determine the level of inequalities in the prevalence of NCDs in various socioeconomic groups (i.e. income and education), the Wagstaff inequality concentration index was estimated. The results are presented in Table 3.

At the national level, the education-based concentration index was -0.338 , which was statistically significant at the $1 \%$ level, demonstrating that the overall prevalence of NCDs is concentrated among the less educated people in the KSA. By gender, both income-based and education-based concentration indices were statistically significant at the $1 \%$ level. Among women, both the 
Table 1 Descriptive statistics of the sample $(N=11,527)$

\begin{tabular}{|c|c|c|}
\hline Variable & Frequency & $\%$ \\
\hline Prevalence of NCDs & 3706 & 32.15 \\
\hline \multicolumn{3}{|l|}{ Age } \\
\hline $18-29$ & 3733 & 32.38 \\
\hline 30-39 & 2398 & 20.80 \\
\hline 40-49 & 1805 & 15.67 \\
\hline $50-59$ & 1569 & 13.61 \\
\hline$\geq 60$ & 2022 & 17.54 \\
\hline \multicolumn{3}{|l|}{ Gender } \\
\hline Female & 5269 & 45.71 \\
\hline Male & 6258 & 54.29 \\
\hline \multicolumn{3}{|l|}{ Marital status } \\
\hline Married & 7395 & 64.15 \\
\hline Unmarried & 4132 & 35.85 \\
\hline \multicolumn{3}{|l|}{ Education level } \\
\hline Below primary school & 2226 & 19.32 \\
\hline Primary school & 1246 & 10.81 \\
\hline Intermediate school & 1893 & 16.42 \\
\hline Secondary school & 3870 & 33.57 \\
\hline Higher education & 2292 & 19.88 \\
\hline \multicolumn{3}{|l|}{ Nationality } \\
\hline Non-Saudi & 2882 & 25.00 \\
\hline Saudi & 8645 & 75.00 \\
\hline \multicolumn{3}{|c|}{ Monthly income (Saudi Riyal) } \\
\hline$<3000$ & 1062 & 9.21 \\
\hline 3000 to $<5000$ & 1851 & 16.06 \\
\hline 5000 to $<7000$ & 1777 & 15.42 \\
\hline 7000 to $<10,000$ & 2220 & 19.26 \\
\hline 10,000 to $<15,000$ & 2173 & 18.85 \\
\hline 15,000 to $<20,000$ & 1118 & 9.70 \\
\hline 20,000 to $<30,000$ & 721 & 6.25 \\
\hline$\geq 30,000$ & 605 & 5.25 \\
\hline \multicolumn{3}{|l|}{ Region } \\
\hline Riyadh & 1652 & 14.33 \\
\hline Albaha & 745 & 6.46 \\
\hline Aljouf & 386 & 3.35 \\
\hline Aseer & 581 & 5.05 \\
\hline Eastern Region & 1049 & 9.10 \\
\hline Haiel & 745 & 6.46 \\
\hline Jazan & 663 & 5.75 \\
\hline Madenah & 834 & 7.23 \\
\hline Mekkah & 2003 & 17.38 \\
\hline Najran & 408 & 3.54 \\
\hline Northern Border & 411 & 3.57 \\
\hline Qassim & 1261 & 10.94 \\
\hline Tabuk & 789 & 6.84 \\
\hline
\end{tabular}


Table 2 Bivariate analysis of the prevalence of NCDs and socio-economic characteristics $(N=11,527)$

\begin{tabular}{|c|c|c|c|}
\hline Variable & Frequency & Percent with NCDs & Chi square \\
\hline Age & & & $520.23^{* * *}$ \\
\hline $18-29$ & 3733 & 5.04 & \\
\hline 30-39 & 2398 & 9.01 & \\
\hline $40-49$ & 1805 & 31.80 & \\
\hline $50-59$ & 1569 & 63.10 & \\
\hline$\geq 60$ & 2022 & 85.95 & \\
\hline Gender & & & $10.51^{* * *}$ \\
\hline Female & 5269 & 33.68 & \\
\hline Male & 6258 & 30.86 & \\
\hline Marital status & & & $404.21^{* * *}$ \\
\hline Married & 7395 & 38.69 & \\
\hline Unmarried & 4132 & 20.45 & \\
\hline Education level & & & $160.63^{* * *}$ \\
\hline Below primary school & 2226 & 64.11 & \\
\hline Primary school & 1246 & 43.82 & \\
\hline Intermediate school & 1893 & 30.48 & \\
\hline Secondary school & 3870 & 17.98 & \\
\hline Higher education & 2292 & 20.07 & \\
\hline Nationality & & & $275.76^{* * *}$ \\
\hline Non-Saudi & 2882 & 19.64 & \\
\hline Saudi & 8645 & 36.32 & \\
\hline Monthly income (Saudi Riyal) & & & $88.26^{* * *}$ \\
\hline$<3000$ & 1062 & 30.32 & \\
\hline 3000 to $<5000$ & 1851 & 33.87 & \\
\hline 5000 to $<7000$ & 1777 & 33.99 & \\
\hline 7000 to $<10,000$ & 2220 & 30.86 & \\
\hline 10,000 to $<15,000$ & 2173 & 30.00 & \\
\hline 15,000 to $<20,000$ & 1118 & 30.14 & \\
\hline 20,000 to $<30,000$ & 721 & 26.77 & \\
\hline$\geq 30,000$ & 605 & 47.27 & \\
\hline Region & & & $274.39^{* * *}$ \\
\hline Riyadh & 1,652 & 32.26 & \\
\hline Albaha & 745 & 38.66 & \\
\hline Aljouf & 386 & 24.09 & \\
\hline Aseer & 581 & 29.78 & \\
\hline Eastern Region & 1,049 & 36.42 & \\
\hline Haiel & 745 & 25.91 & \\
\hline Jazan & 663 & 17.95 & \\
\hline Madenah & 834 & 30.58 & \\
\hline Mekkah & 2,003 & 34.30 & \\
\hline Najran & 408 & 20.83 & \\
\hline Northern Border & 411 & 14.60 & \\
\hline Qassim & 1,261 & 42.66 & \\
\hline Tabuk & 789 & 38.02 & \\
\hline
\end{tabular}

${ }^{* * *} p<0.01,{ }^{* *} p<0.05,{ }^{*} p<0.1$ 
Table 3 Wagstaff inequality indices for the prevalence of NCDs by income and education $(N=11,527)$

\begin{tabular}{|c|c|c|c|c|}
\hline & \multicolumn{2}{|l|}{ Income } & \multicolumn{2}{|l|}{ Education } \\
\hline & Index estimate & $95 \% \mathrm{Cl}$ & Index estimate & $95 \% \mathrm{Cl}$ \\
\hline National level & 0.003 & $(-0.020$ to 0.025$)$ & $-0.338^{* * *}$ & $(-0.358$ to -0.316$)$ \\
\hline \multicolumn{5}{|l|}{ Gender } \\
\hline Female & $-0.128^{* * *}$ & $(-0.160$ to -0.095$)$ & $-0.513^{* * *}$ & $(-0.541$ to 0.484$)$ \\
\hline Male & $0.113^{* * *}$ & (0.083 to 0.144$)$ & $-0.173^{* * *}$ & $(-0.203$ to -0.144$)$ \\
\hline \multicolumn{5}{|l|}{ Regions } \\
\hline Riyadh & 0.002 & $(-0.056$ to 0.061$)$ & $-0.202^{* * *}$ & $(-0.259$ to -0.145$)$ \\
\hline Albaha & $-0.098^{* *}$ & $(-0.181$ to -0.015$)$ & $-0.434^{* * *}$ & $(-0.511$ to -0.357$)$ \\
\hline Aljouf & $-0.123^{*}$ & $(-0.253$ to 0.009$)$ & $-0.298^{* * *}$ & $(-0.425$ to -0.171$)$ \\
\hline Aseer & 0.049 & $(-0.053$ to 0.151$)$ & $-0.352^{* * *}$ & $(-0.446$ to -0.253$)$ \\
\hline Eastern Region & -0.044 & $(-0.115$ to 0.028$)$ & $-0.310^{* * *}$ & $(-0.377$ to -0.243$)$ \\
\hline Haiel & $0.095^{* *}$ & (0.001 to 0.188$)$ & $-0.542^{* * *}$ & $(-0.625$ to 0.459$)$ \\
\hline Jazan & -0.084 & $(-0.196$ to 0.029$)$ & $-0.412^{* * *}$ & $(-0.518$ to -0.305$)$ \\
\hline Madenah & $-0.190^{* * *}$ & $(-0.272$ to -0.107$)$ & $-0.585^{* * *}$ & $(-0.658$ to -0.513$)$ \\
\hline Mekkah & $-0.076^{* * *}$ & $(-0.128$ to 0.024$)$ & $-0.276^{* * *}$ & $(-0.326$ to -0.225$)$ \\
\hline Najran & -0.112 & $(-0.248$ to 0.024$)$ & $-0.550^{* * *}$ & $(-0.672$ to -0.428$)$ \\
\hline Northern Border & $0.333^{* * *}$ & (0.180 to 0.484$)$ & $-0.253^{* * *}$ & (-0.404 to 0.102$)$ \\
\hline Qassim & $0.147^{* * *}$ & (0.083 to 0.209 ) & $-0.233^{* * *}$ & $(-0.294$ to -0.172$)$ \\
\hline Tabuk & $-0.122^{* * *}$ & $(-0.203$ to -0.041$)$ & $-0.611^{* * *}$ & $(-0.679$ to -0.542$)$ \\
\hline
\end{tabular}

*** $p<0.01,{ }^{* *} p<0.05,{ }^{*} p<0.1$

income-based and education-based indices were significantly negative, indicating that the prevalence of NCDs is concentrated among women with a lower income level and with less education. By contrast, the income-based concentration index among men was significantly positive, indicating that the prevalence of NCDs is concentrated among men with a higher income level.

Although the education-based concentration indices were negative and statistically significant at the $1 \%$ level for all regions, this was not the case for the incomebased concentration indices across regions. For some regions, the inequality indices were either not significantly negative or were significantly positive. For instance, the income-based concentration indices in Hail $(0.095, p<$ $0.05)$, Northern Border (0.333, $p<0.01)$, and Qassim $(0.147, p<0.01)$ were positive and statistically significant. In Riyadh and Aseer, the income-based indices were also positive but were not statistically significant, whereas the negative income-based indices in the Eastern Region, Jazan, and Najran were statistically insignificant.

Figures 1 and 2 depict the concentration curves by income and education, respectively. Figure 1 shows that the income-based concentration curve for people with NCDs almost perfectly overlaps with the line of equality, suggesting no inequality. By contrast, Fig. 2 confirms that the prevalence of NCDs is disproportionately concentrated among less educated people in the KSA, as the concentration curve (blue) is above the red line of equality.

\section{Regression analysis}

Given that the univariate and bivariate analyses did not consider other variables that might influence the association between the prevalence of NCDs and socioeconomic factors, a multivariate logistic regression analysis was further performed. Table 4 summarises the results from the logistic regression analysis to examine the socio-economic factors associated with the prevalence of NCDs.

The likelihood of reporting NCDs was lower among the higher-income groups (except those who earn $\geq$ 30,000 SR) compared with the lower income groups, as revealed by Model 1 . For example, the odds ratio (OR) was 0.629 (95\% CI: $0.469-0.844, p<0.01$ ) for people with a reported income level of 20,000 to < 30,000 SR. Model 2 indicated that the likelihood of reporting NCDs was lower among people with a higher education (OR: 0.599, $95 \%$ CI: 0.497-0.723, $p<0.01)$ compared with that of people with an education below the primary school level. The OR of education categories remained statistically significant in Model 3. Model 3 also revealed the higher likelihood of reporting NCDs among people aged $\geq 60$ years (OR: 126.62, $95 \%$ CI: 99.256-161.532, $p<0.01$ ) compared with that of younger people.

In addition, the likelihood of reporting NCDs among unmarried people was higher compared with that of married people (OR: 1.51, $95 \%$ CI: 1.277-1.775, $p<$ 


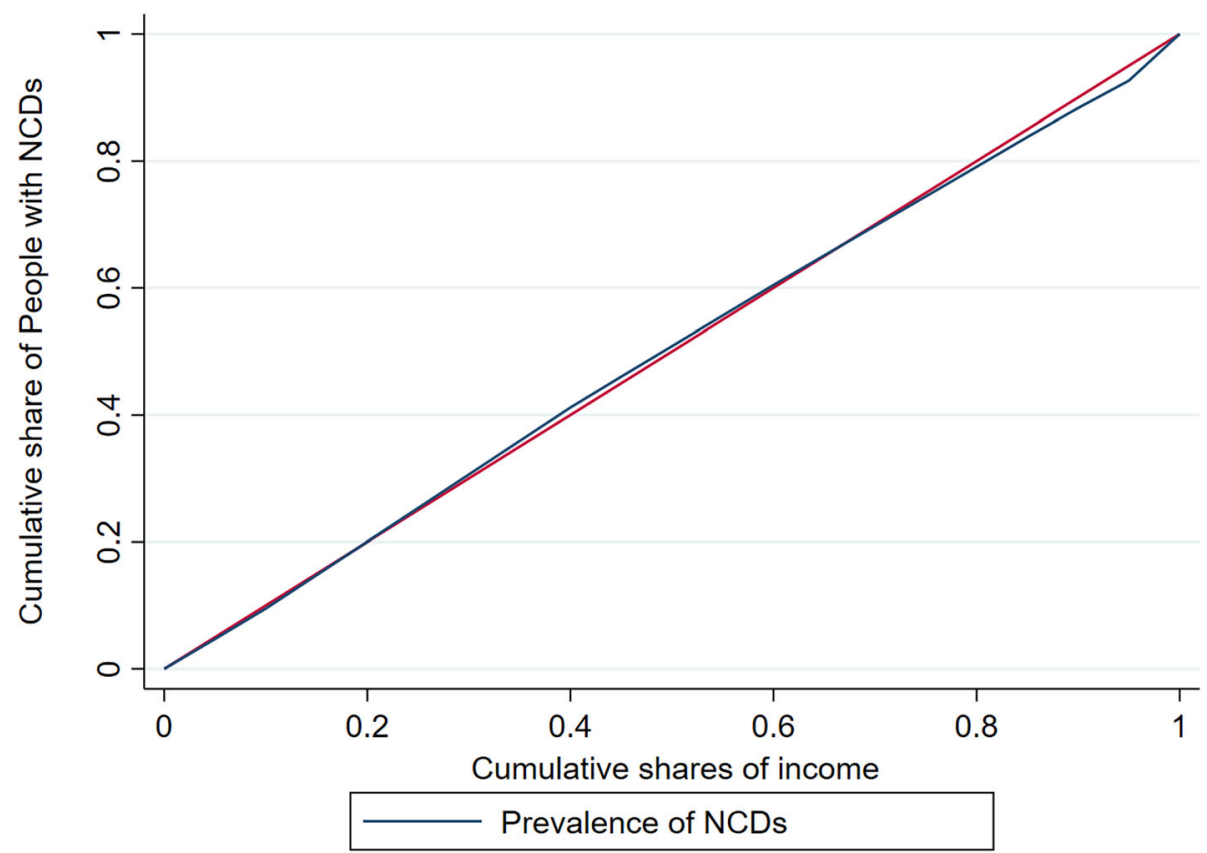

Fig. 1 Income-based concentration curve

0.01). Moreover, the OR for the regional dummy variable suggested that there are regional differences in the likelihood of reporting NCDs. Specifically, residents in most of regions, except for Qassim (OR: 1.243, 95 \% CI: $1.006-1.536, p<0.05)$, were less likely to report NCDs than those in Riyadh.
Given that covariate measurement error via misclassification of categorical independent variables in the regression analysis may potentially pose a threat to the validity of parameter estimates and statistical inferences, the study also conducted a sensitivity analysis via reestimation by bootstrap and jackknife approaches. The

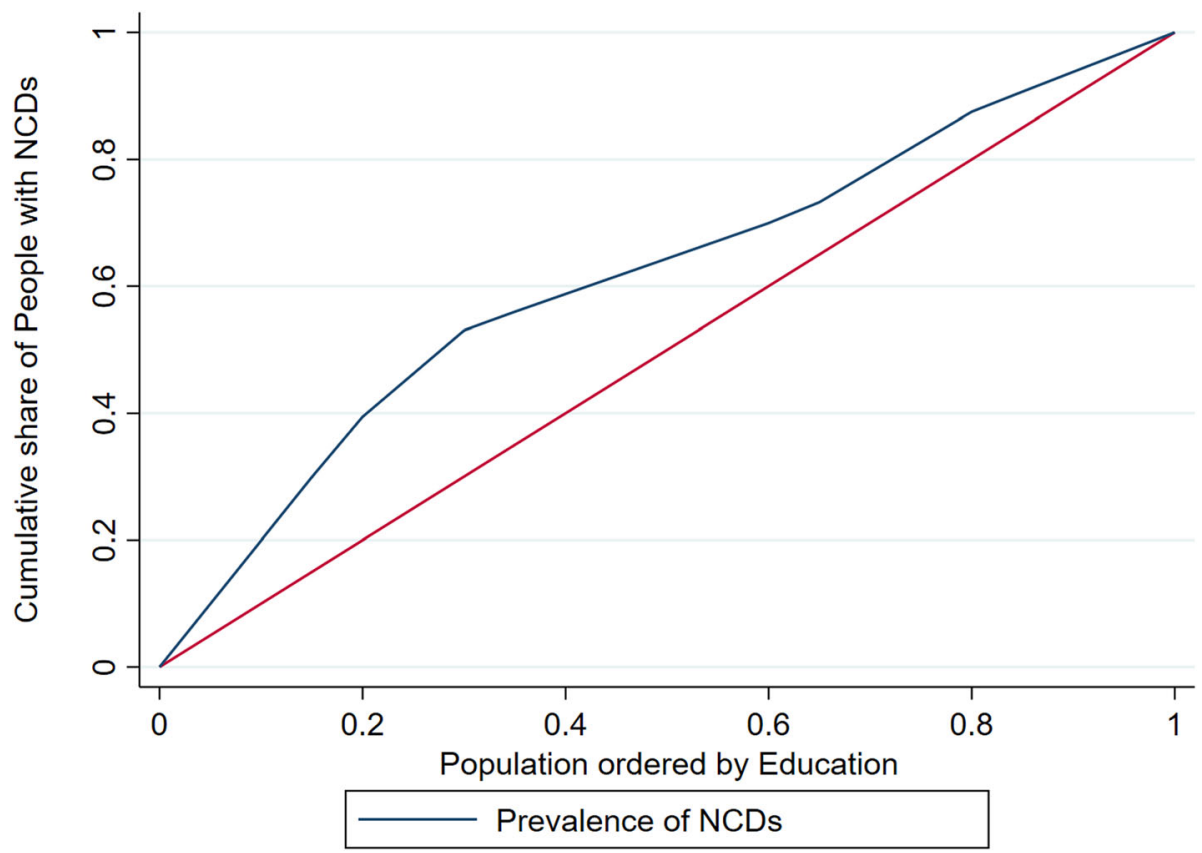

Fig. 2 Education-based concentration curve 
Table 4 Association between the prevalence of NCDs and socio-economic factors (logistic regression)

\begin{tabular}{|c|c|c|c|c|c|c|}
\hline \multirow[t]{2}{*}{ Variables } & \multicolumn{2}{|l|}{ Model 1} & \multicolumn{2}{|l|}{ Model 2} & \multicolumn{2}{|l|}{ Model 3} \\
\hline & OR & $95 \% \mathrm{Cl}$ & OR & $95 \% \mathrm{Cl}$ & OR & $95 \% \mathrm{Cl}$ \\
\hline \multicolumn{7}{|l|}{ Age } \\
\hline $18-29$ & Reference & & Reference & & Reference & \\
\hline 30-39 & $2.662^{* * *}$ & $(2.123-3.337)$ & $2.761^{* * *}$ & $(2.194-3.475)$ & $2.764^{* * *}$ & $(2.196-3.478)$ \\
\hline $40-49$ & $13.069^{* * *}$ & $(10.510-16.250)$ & $12.422^{* * *}$ & $(9.929-15.542)$ & $12.537^{* * *}$ & (10.019-15.689) \\
\hline $50-59$ & $46.303^{* * *}$ & (37.219-57.603) & $42.104^{* * *}$ & (33.521-52.885) & $42.423^{* * *}$ & (33.764-53.303) \\
\hline$\geq 60$ & $149.848^{* * *}$ & (119.820-187.401) & $125.850^{* * *}$ & (98.683-160.496) & $126.621^{* * *}$ & (99.256-161.532) \\
\hline \multicolumn{7}{|l|}{ Gender } \\
\hline Female & Reference & & Reference & & Reference & \\
\hline Male & $0.849^{* * *}$ & $(0.759-0.950)$ & 0.924 & $(0.823-1.038)$ & 0.915 & $(0.814-1.029)$ \\
\hline \multicolumn{7}{|l|}{ Marital status } \\
\hline Married & Reference & & Reference & & Reference & \\
\hline Unmarried & $1.543^{* * *}$ & $(1.312-1.814)$ & $1.526^{* * *}$ & $(1.296-1.799)$ & $1.506^{* * *}$ & $(1.277-1.775)$ \\
\hline \multicolumn{7}{|l|}{ Education level } \\
\hline Below primary school & & & Reference & & Reference & \\
\hline Primary school & & & 0.877 & $(0.723-1.063)$ & 0.900 & $(0.741-1.093)$ \\
\hline Intermediate school & & & 1.055 & $(0.873-1.275)$ & 1.107 & (0.912-1.344) \\
\hline Secondary school & & & $0.622^{* * *}$ & $(0.523-0.740)$ & $0.654^{* * *}$ & $(0.546-0.784)$ \\
\hline Higher education & & & $0.599^{* * *}$ & $(0.497-0.723)$ & $0.650^{* * *}$ & $(0.531-0.795)$ \\
\hline \multicolumn{7}{|l|}{ Nationality } \\
\hline Non-Saudi & Reference & & Reference & & Reference & \\
\hline Saudi & $1.962^{* * *}$ & $(1.697-2.267)$ & $1.853^{* * *}$ & $(1.616-2.125)$ & $1.921^{* * *}$ & $(1.662-2.223)$ \\
\hline \multicolumn{7}{|c|}{ Monthly income (Saudi Riyal) } \\
\hline$<3000$ & Reference & & & & Reference & \\
\hline 3000 to $<5000$ & 1.103 & $(0.875-1.391)$ & & & 1.131 & $(0.896-1.427)$ \\
\hline 5000 to $<7000$ & 1.074 & $(0.849-1.359)$ & & & 1.139 & $(0.899-1.443)$ \\
\hline 7000 to $<10,000$ & $0.803^{*}$ & $(0.637-1.011)$ & & & 0.907 & $(0.716-1.150)$ \\
\hline 10,000 to $<15,000$ & $0.765^{* *}$ & $(0.606-0.966)$ & & & 0.886 & $(0.696-1.127)$ \\
\hline 15,000 to $<20,000$ & $0.729^{* *}$ & $(0.561-0.947)$ & & & 0.868 & $(0.661-0.1 .139)$ \\
\hline 20,000 to $<30,000$ & $0.629^{* * *}$ & $(0.469-0.844)$ & & & $0.760^{*}$ & $(0.560-1.032)$ \\
\hline$\geq 30,000$ & 1.202 & $(0.879-1.645)$ & & & $1.506^{* *}$ & $(1.089-2.083)$ \\
\hline \multicolumn{7}{|l|}{ Region } \\
\hline Riyadh & Reference & & Reference & & Reference & \\
\hline Albaha & $0.710^{* * *}$ & $(0.551-0.914)$ & $0.688^{* * *}$ & $(0.534-0.887)$ & $0.688^{* * *}$ & $(0.533-0.888)$ \\
\hline Aljouf & $0.543^{* * *}$ & $(0.379-0.777)$ & $0.573^{* * *}$ & $(0.403-0.816)$ & $0.540^{* * *}$ & $(0.377-0.773)$ \\
\hline Aseer & $0.708^{* *}$ & $(0.531-0.945)$ & $0.688^{* *}$ & $(0.515-0.918)$ & $0.664^{* * *}$ & $(0.497-0.888)$ \\
\hline Eastern Region & $0.639^{* * *}$ & $(0.510-0.802)$ & $0.645^{* * *}$ & $(0.514-0.809)$ & $0.636^{* * *}$ & $(0.506-0.800)$ \\
\hline Haiel & $0.545^{* * *}$ & $(0.416-0.713)$ & $0.565^{* * *}$ & $(0.432-0.740)$ & $0.527^{* * *}$ & $(0.402-0.691)$ \\
\hline Jazan & $0.414^{* * *}$ & $(0.308-0.556)$ & $0.421^{* * *}$ & $(0.313-0.565)$ & $0.419^{* * *}$ & $(0.312-0.563)$ \\
\hline Madenah & $0.649^{* * *}$ & $(0.505-0.832)$ & $0.674^{* * *}$ & $(0.527-0.862)$ & $0.641^{* * *}$ & $(0.498-0.824)$ \\
\hline Mekkah & 1.046 & $(0.865-1.266)$ & 1.069 & $(0.886-1.291)$ & 1.028 & $(0.849-1.245)$ \\
\hline Najran & $0.440^{* * *}$ & $(0.314-0.616)$ & $0.412^{* * *}$ & $(0.294-0.578)$ & $0.416^{* * *}$ & $(0.297-0.584)$ \\
\hline Northern border & $0.412^{* * *}$ & $(0.280-0.606)$ & $0.408^{* * *}$ & $(0.277-0.602)$ & $0.374^{* * *}$ & $(0.252-0.555)$ \\
\hline Qassim & $1.263^{* *}$ & $(1.023-1.556)$ & $1.330^{* * *}$ & $(1.080-1.636)$ & $1.243^{* *}$ & (1.006-1.536) \\
\hline
\end{tabular}


Table 4 Association between the prevalence of NCDs and socio-economic factors (logistic regression) (Continued)

\begin{tabular}{|c|c|c|c|c|c|c|}
\hline \multirow[t]{2}{*}{ Variables } & \multicolumn{2}{|l|}{ Model 1} & \multicolumn{2}{|l|}{ Model 2} & \multicolumn{2}{|l|}{ Model 3} \\
\hline & OR & $95 \% \mathrm{Cl}$ & OR & $95 \% \mathrm{Cl}$ & OR & $95 \% \mathrm{Cl}$ \\
\hline Tabuk & $0.797^{*}$ & $(0.619-1.027)$ & $0.783^{*}$ & $(0.608-1.008)$ & $0.765^{* *}$ & $(0.592-0.987)$ \\
\hline Constant & $0.033^{* * *}$ & $(0.024-0.046)$ & $0.040^{* * *}$ & $(0.029-0.054)$ & $0.039^{* * *}$ & $(0.027-0.055)$ \\
\hline Observations & 11,527 & & 11,527 & & 11,527 & \\
\hline Pseudo R-squared & 0.408 & & 0.410 & & 0.411 & \\
\hline Chi-squared & $5901^{* * *}$ & & $5922^{* * *}$ & & $5954^{* * *}$ & \\
\hline
\end{tabular}

Note. $95 \%$ confidence intervals are in parentheses; Abbreviation: OR, odds ratio; ${ }^{* *} p<0.01,{ }^{* *} p<0.05$, ${ }^{*} p<0.1$

OR findings in the bootstrap and jackknife estimation approaches were consistent with the initial findings (Appendix 1), suggesting that the model was robust to any likely measurement error.

\section{Discussion}

This is the first study to investigate socio-economic determinants and inequalities in the prevalence of NCDs in the KSA using a vast dataset with national representativeness. These characteristics distinguish this study from previous studies that analysed the prevalence of specific types of NCDs among diverse groups [4, 31]. The findings showed that the prevalence of NCDs in the KSA is $32.15 \%$. Moreover, there were significant inequalities found in the prevalence of NCDs in the KSA across socio-economic characteristics. Aside from health repercussions, the high rate of the prevalence of NCDs and the existence of inequalities have adverse effects on the economy. NCDs affect the quality of health of the labour force, thereby leading to reduction in labour productivity [32]. This has a negative impact on the economy as it hinders growth of the gross domestic product (GDP) per capita and places a huge financial burden on the government for health expenditure [33, 34]. In Saudi Arabia, an economic burden analysis showed that economic losses from NCDs are equivalent to $2.8 \%$ of the GDP [35]. Such effects are worse among vulnerable groups that are more susceptible to NCDs. By reducing their economic activity, NCDs have the potential to keep the vulnerable population in a cycle of struggles and in an inescapable poverty trap [36]. Therefore, there is a dire need to implement control and prevention strategies that account for existing socioeconomic inequalities in the prevalence of NCDs.

The results showed that the prevalence of NCDs is significantly associated with gender and is more concentrated among women than men. More specifically, the results showed that the prevalence of NCDs is concentrated among women with a lower income level and with less education. These findings correlate with results from other studies [2, 37-39]. Women generally live longer than men due to a higher rate of death by external causes among men [31]. The high life expectancy among women makes them susceptible to NCDs, which are highly prevalent among the aging population. Moreover, women use healthcare services more frequently due to their greater sensitivity to physical symptoms than men [37]. As such, women are more likely to receive a diagnosis than men in self-reported studies. Accordingly, it is important for countries to consider health strategies that address gender-based inequalities in the prevalence of NCDs. In Saudi Arabia, one of the focus areas in the implementation of Vision 2030 is to close the gap between men and women in personal income, education, and labour force participation [19]. Without addressing these challenges, the contribution of women to the economic development of the country would be greatly undermined.

Regarding age, the likelihood of reporting NCDs was higher among elderly people aged $\geq 60$ years compared with that of younger people. This is coherent with the literature showing higher occurrences of NCDs among the elderly population $[17,38,40,41]$. Furthermore, the prevalence of NCDs appears to be concentrated among the less educated people in Saudi Arabia. Contrasting the prevalence for highly educated people $(20.07 \%)$ and those with a secondary school level of education $(17.98 \%)$, the prevalence of NCDs was $64.11 \%$ among people with no schooling or education below the primary level. The logistic regression also indicated a lower OR of NCDs prevalence among people with higher education (0.599, $95 \%$ CI: 0.497-0.723, p<0.01) compared with that of people with an education below the primary school level. However, this is not a surprising result as previous studies have shown a high association between a low socio-economic status and high prevalence of NCDs [42].

There were also regional differences found in the likelihood of reporting chronic diseases as shown by the OR for the regional dummy variable. Moreover, the education-based concentration indices were negative and statistically significant at the $1 \%$ level for all regions. This is in line with findings from other studies showing that urban and rural regions exhibited different prevalence levels [18, 40, 43, 44]. These findings are mainly due to disparities in healthcare access 
and healthcare resources, diverse cultural norms and practices, as well as limited availability of healthcare facilities in different regions of a country [17]. Such regional differences can exacerbate socio-economic inequalities in the prevalence of NCDs, and have the potential to widen the gap between the rich and the poor in the country.

The prevalence of chronic diseases was also significantly associated with nationality. NCDs were found to be more heavily concentrated among Saudis than non-Saudis. The differences in lifestyle between nationals and expatriates might explain this high prevalence rate of NCDs among Saudi nationals, as there is evidence demonstrating that physical inactivity and consumption of an unhealthy diet (risk factors for NCDs) are common and significantly high among adult Saudi citizens [10, 45]. Similar findings were also found in other Arab countries sharing similar customs and traditions [46]. Moreover, this study demonstrated a lower likelihood of reporting chronic disease among higher-income groups (except those earning more than 30,000 SR) compared with that of lower-income groups. A potential explanation for this difference is that at very high levels of income (i.e. those who earn more than 30,000 SR in Saudi Arabia), the prevalence rate of NCDs increases as people become more susceptible to risk factors such as by increasing physical inactivity and unhealthy habits. This result related to the highest income level agrees with results observed in China [47].

This study has several advantages. The analysis involved a rich dataset with a nationally representative sample. This study also applied multiple techniques to reduce method-based findings and conclusions. Therefore, the findings are relevant for informing the design and implementation of control and prevention mechanism for NCDs. Nevertheless, there are a few limitations associated with this study. The data utilized are subject to recall biases as they are self-reported. Future analyses should consider using different types of data or applying standardized measures that could reduce the effect of self-reported data. In addition, disparities in the reported prevalence of NCDs could reflect differential access to healthcare services. There might be higher reports from people with access to a diagnosis than those lacking such access. In this case, the results might be capturing access to diagnosis instead of the true existence of NCDs. This is because the absence of self-reported prevalence might indicate absence of a diagnosis rather than the absence of NCDs. These are some of the issues that future studies need to consider when conducting similar analyses.

\section{Conclusions}

Using data from the 2018 Saudi FHS, this study examined the socio-economic determinants and inequalities in the prevalence of NCDs in the KSA. The general prevalence of NCDs was found to be $32.15 \%$, and the results established the existence of significant inequalities in the prevalence of NCDs in the KSA. The prevalence of NCDs was higher among women and among elderly people aged 60 years and above. The likelihood of reporting NCDs was also higher among people with lower education levels. These inequalities have been shown to have adverse health as well as economic effects, as they have the potential to derail economic development. There is a need to monitor the progression of risk factors and develop targeted intervention strategies to control NCDs and achieve health equality. Such control and prevention mechanisms must consider socio-economic status, as well as factors such as age, marital status, nationality, and region of residence. This is a prerequisite if such strategies are to be effective in addressing the challenges of rapid population ageing, socio-economic inequalities, and negative economic effects.

\section{Supplementary information}

The online version contains supplementary material available at https://doi. org/10.1186/s12939-021-01510-6.

Additional file 1 Appendix 1: A sensitivity analysis via re-estimation by bootstrap and jackknife approaches.

\section{Acknowledgements}

The author is grateful to the anonymous referees for any comments and suggestions that helped to produce the manuscript in its current form.

\section{Authors' contributions \\ Conceptualization, M.K.A.; data curation, M.K.A.; formal analysis, M.K.A.; investigation, M.K.A.; methodology, M.K.A.; project administration, M.K.A.; software, M.K.A.; writing —original draft preparation, M.K.A.; writing-review and editing, M.K.A. The author have read and approved the final manuscript.}

\section{Funding}

The author received no financial support for the research, authorship, and/or publication of this article.

\section{Availability of data and materials}

The datasets generated and/or analysed during the current study are not publicly available due to privacy, confidentiality, and other restrictions. Access to data can be gained through the General Authority for Statistics in Saudi Arabia via https://www.stats.gov.sa/en.

\section{Declarations}

Ethics approval and consent to participate

This study did not require ethical approval because only secondary data were used in the analysis. Furthermore, the data were de-identified. The outcomes of the analysis do not allow for re-identification and the use of data cannot result in any damage or distress to the participants.

Consent for publication

Not applicable.

Competing interest

The author declares no competing interests. 
Received: 1 April 2021 Accepted: 9 July 2021

Published online: 28 July 2021

\section{References}

1. Wagner $\mathrm{K}-\mathrm{H}$, Brath $\mathrm{H}$. A global view on the development of non communicable diseases. Preventive medicine. 2012;54:38-41.

2. Habib SH, Saha S. Burden of non-communicable disease: global overview. Diabetes Metabolic Syndrome: Clinical Research Reviews. 2010;4(1):41-7.

3. Hazazi A, Chandramohan S. Strengthening the Health Care System to Address the New Challenge of Non-Communicable Diseases in the Kingdom Of Saudi Arabia: A Systematic Review. International Journal of Scientific Study. 2017;5(7):114-20.

4. Mandil AM, Alfurayh NA, Aljebreen MA, Aldukhi SA. Physical activity and major non-communicable diseases among physicians in Central Saudi Arabia. Saudi Med J. 2016;37(11):1243.

5. WHO. Noncommunicable diseases: key facts 2018 [cited $202110 \mathrm{March}$; Available from: https://www.who.int/news-room/fact-sheets/detail/ noncommunicable-diseases.

6. Tyrovolas S, El Bcheraoui C, Alghnam SA, Alhabib KF, Almadi MAH, AlRaddadi RM, et al. The burden of disease in Saudi Arabia 1990-2017: results from the Global Burden of Disease Study 2017. The Lancet Planetary Health. 2020:4(5):e195-208.

7. Al-Nozha MM, Abdullah M, Arafah MR, Khalil MZ, Khan NB, Al-Mazrou YY, et al. Hypertension in saudi arabia. Saudi Med J. 2007;28(1):77-84.

8. Al-Hanawi MK, Chirwa GC, Pemba LA, Qattan AM. Does prolonged television viewing affect Body Mass Index? A case of the Kingdom of Saudi Arabia. Plos one. 2020;15(1):e0228321.

9. Al-Hanawi MK, Chirwa GC, Pulok MH. Socio-economic inequalities in diabetes prevalence in the Kingdom of Saudi Arabia. Int J Health Plan Manag. 2020;35(1):233-46.

10. Mahmood FM. Prevalence and prevention of lifestyle-related diseases in Saudi Arabia. International journal of health sciences. 2018;12(5):1.

11. Herzallah HK, Antonisamy BR, Shafee MH, Al-Otaibi ST. Temporal trends in the incidence and demographics of cancers, communicable diseases, and non-communicable diseases in Saudi Arabia over the last decade. Saudi Med J. 2019;40(3):277.

12. Khaliq AA. The Saudi health care system: a view from the minaret. World health population. 2012;13(3):52-64

13. Khoja AT, Aljawadi MH, Al-Shammari SA, Mohamed AG, Al-Manaa HA, Morlock L, et al. The health of Saudi older adults; results from the Saudi National Survey for Elderly Health (SNSEH) 2006-2015. Saudi Pharmaceutical Journal. 2018;26(2):292-300.

14. Khademi N, Babanejad M, Asadmobini A, Karim H. The association of age and gender with risk factors of noncommunicable diseases among employees in West of Iran. Int J Prev Med. 2017;8:9.

15. Sommer I, Griebler U, Mahlknecht P, Thaler K, Bouskill K, Gartlehner G, et al. Socioeconomic inequalities in non-communicable diseases and their risk factors: an overview of systematic reviews. BMC Public Health. 2015;15(1):1-12.

16. Biswas T, Islam MS, Linton N, Rawal LB. Socio-economic inequality of chronic non-communicable diseases in Bangladesh. Plos one. 2016;11(11): e0167140

17. Lai S, Shen C, Yang X, Zhang X, Xu Y, Li Q, et al. Socioeconomic inequalities in the prevalence of chronic diseases and preventive care among adults aged 45 and older in Shaanxi Province, China. BMC Public Health. 2019; 19(1):1-12.

18. Vellakkal S, Subramanian S, Millett C, Basu S, Stuckler D, Ebrahim S. Socioeconomic inequalities in non-communicable diseases prevalence in India: disparities between self-reported diagnoses and standardized measures. Plos one. 2013;8(7):e68219.

19. Bawazir A, Al-Surimi K, Suwaidan SD, AIShehri AM, AlFarhan Al, Abolfotouh MA Capacity and readiness of primary health care centers for implementation of the basic strategy for prevention and control of non-communicable diseases in Saudi Arabia. A case study from the Ministry of National Guard-Health Affairs, Riyadh, Saudi Arabia. Saudi Med J. 2019;40(6):614-8.

20. Forest JJ, Sousa MV. Oil and terrorism in the New Gulf: framing US energy and security policies for the Gulf of Guinea. Lanham: Lexington Books; 2006.

21. Al-Hanawi MK, Alsharqi O, Almazrou S, Vaidya K. Healthcare finance in the Kingdom of Saudi Arabia: a qualitative study of householders' attitudes. Appl Health Econ Health Policy. 2018;16(1):55-64.
22. Haque MI, Khan MR. Role of oil production and government expenditure in improving human development index: Evidence from Saudi Arabia. International Journal of Energy Economics Policy. 2019;9(2):251.

23. GASTAT. The General Authority for Statistics. 2020 [cited 202120 Feb]; Available from: https://www.stats.gov.sa/en/43.

24. GASTAT. The General Authority for Statistics: Family Health Survey. 2018 [cited 20211 Jan]; Available from: https://www.stats.gov.sa/en/965.

25. Lyles RH, Lin J. Sensitivity analysis for misclassification in logistic regression via likelihood methods and predictive value weighting. Statistics in medicine. 2010;29(22):2297-309.

26. Wagstaff A, Paci P, Van Doorslaer E. On the measurement of inequalities in health. Soc Sci Med. 1991;33(5):545-57.

27. Qattan A, Boachie MK, Immurana M, Al-Hanawi MK. Socioeconomic Determinants of Smoking in the Kingdom of Saudi Arabia. International Journal of Environmental Research Public Health. 2021; 18(11):5665.

28. Pande RP, Yazbeck AS. What's in a country average? Wealth, gender, and regional inequalities in immunization in India. Soc Sci Med. 2003;57(11):2075-88.

29. Thomson KH, Renneberg A-C, McNamara CL, Akhter N, Reibling N, Bambra C. Regional inequalities in self-reported conditions and non-communicable diseases in European countries: findings from the European Social Survey (2014) special module on the social determinants of health. The European Journal of Public Health. 2017:27(suppl 1):14-21.

30. O'donnell O, Van Doorslaer E, Wagstaff A, Lindelow M. Analyzing health equity using household survey data: a guide to techniques and their implementation. The World Bank; 2007

31. AlQuaiz AM, Siddiqui AR, Qureshi RH, Fouda MA, AlMuneef MA, Habib FA, et al. Women Health in Saudi Arabia: A review of non-communicable diseases and their risk factors. Pakistan journal of medical sciences. 2014; 30(2):422

32. Chaker L, Falla A, van der Lee SJ, Muka T, Imo D, Jaspers L, et al. The global impact of non-communicable diseases on macro-economic productivity: a systematic review. Eur J Epidemiol. 2015;30(5):357-95.

33. Sweeny $K$, Rasmussen B, Sheehan P. The Impact of Health on Worker Attendance and Productivity in Twelve Countries. 2015

34. Bloom DE, Chen S, McGovern ME The economic burden of noncommunicable diseases and mental health conditions: results for Costa Rica, Jamaica, and Peru. Revista Panamericana de Salud Pública. 2018;42:e18.

35. UNDP. Prevention and Control of Noncommunicable Diseases in the Kingdom of Saudi Arabia: The Case for Investment. 2017 [cited 202127 March]; Available from: https://www.sa.undp.org/content/saudi_arabia/en/ home/library/poverty/prevention-and-control-of-noncommunicable-disea ses-in-the-kingdo.html.

36. Jan S, Laba T-L, Essue BM, Gheorghe A, Muhunthan J, Engelgau M, et al. Action to address the household economic burden of non-communicable diseases. The Lancet. 2018:391(10134):2047-58.

37. Alonso J, Ferrer M, Gandek B, Ware JE, Aaronson NK, Mosconi P, et al. Health-related quality of life associated with chronic conditions in eight countries: results from the International Quality of Life Assessment (IQOLA) Project. Quality of life research. 2004;13(2):283-98.

38. Schmidt MI, Duncan BB, e Silva GA, Menezes AM, Monteiro CA, Barreto SM, et al. Chronic non-communicable diseases in Brazil: burden and current challenges. The Lancet. 2011;377(9781):1949-61.

39. Yin $\mathrm{H}$, Wu O, Cui $Y$, Hao Y, Liu C, Li Y, et al. Socioeconomic status and prevalence of chronic non-communicable diseases in Chinese women: a structural equation modelling approach. BMJ open. 2017; 7(8):e014402.

40. Kunna R, San Sebastian M, Williams JS. Measurement and decomposition of socioeconomic inequality in single and multimorbidity in older adults in China and Ghana: results from the WHO study on global AGEing and adult health (SAGE). Int J Equity Health. 2017;16(1):1-17.

41. Le DD, Leon-Gonzalez R, Giang TL, Nguyen AT. Socio-economic-related health inequality in non-communicable diseases among older people in Viet Nam. Ageing Soc. 2021;1421-48.

42. WHO. Global action plan for the prevention and control of noncommunicable diseases 2013-2020. World Health Organization; 2013.

43. Costa CdS, Flores TR, Wendt A, Neves RG, Tomasi E, Cesar JA, et al. Inequalities in multimorbidity among elderly: a population-based study in a city in Southern Brazil. Cadernos de saude publica. 2018;34(11): e00040718. 
44. Miranda JJ, Kinra S, Casas JP, Davey Smith G, Ebrahim S. Non-communicable diseases in low and middle income countries: context, determinants and health policy. Tropical Med Int Health. 2008;13(10):1225-34.

45. Al-Hanawi MK, Keetile M. Socio-economic and demographic correlates of non-communicable disease risk factors among adults in Saudi Arabia. Front Med. 2021;8:605912.

46. Hamoudi R, Sharif-Askari NS, Sharif-Askari FS, Abusnana S, Aljaibeji H, Taneera J, et al. Prediabetes and diabetes prevalence and risk factors comparison between ethnic groups in the United Arab Emirates. Scientific reports. 2019;9(1):1-7.

47. Xie $X$, Wu Q, Hao Y, Yin H, Fu W, Ning N, et al. Identifying determinants of socioeconomic inequality in health service utilization among patients with chronic non-communicable diseases in China. Plos one. 2014;9(6):e100231.

\section{Publisher's Note}

Springer Nature remains neutral with regard to jurisdictional claims in published maps and institutional affiliations.

Ready to submit your research? Choose BMC and benefit from:

- fast, convenient online submission

- thorough peer review by experienced researchers in your field

- rapid publication on acceptance

- support for research data, including large and complex data types

- gold Open Access which fosters wider collaboration and increased citations

- maximum visibility for your research: over $100 \mathrm{M}$ website views per year

At $\mathrm{BMC}$, research is always in progress.

Learn more biomedcentral.com/submissions 